\title{
Experimental Investigation of Four Switch Three Phase Inverter Performance Fed Sensorless Speed Control of Induction Motor Drives
}

\author{
Mohamed K. Metwally and Haitham Z. Azazi \\ Electrical Engineering Department, Faculty of Engineering, Shebin El-Kom, \\ Minoufiya University, Egypt
}

\begin{abstract}
This paper presents an experimental investigation of four switch inverter performance fed three phase induction motor drives. The speed estimation based on fundamental wave models using model reference adaptive system as speed estimator technique. The motor is fed from four switch three phase inverter. A comparative study for sensorless speed estimation using four switch three phase inverter and six switch inverter is experimentally investigated. Also a comparison of system performance based on four switch inverter and conventional six switch inverter in terms of speed response and total harmonic distortion of stator currents is presented. Experimental results at different point of operations are presented verifying robustness of sensorless speed estimation at different load levels. Sensorless speed estimation based on four switch three phase inverter is quite acceptable considering its speed response.
\end{abstract}

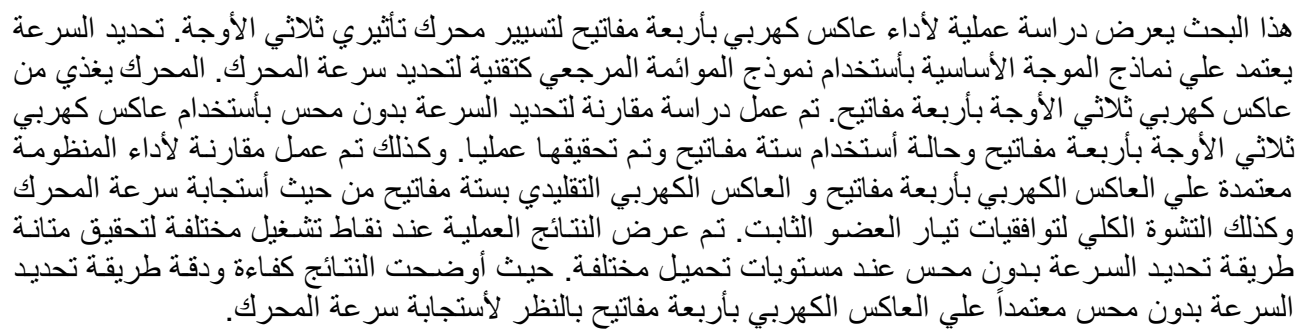

Keywords: Induction motor, Four switch inverter, Six switch inverter, Sensorless control, model reference adaptive system (MRAS), total harmonic distortion(THD) and digital signal processor (DSP).

\section{INTRODUCTION}

Induction Three phase variable speed drives for asynchronous motors have been used more and more, especially in energy saving drive applications. Nowadays, a few research efforts have been directed to develop power converters with reduced losses and cost for driving induction motors. Hence, a reduced number of inverter switches is promising solution. Among them the four switch three phase inverter (FSTPI) was introduced with four IGBT switches instead of six switch three phase inverter (SSTPI). The FSTP inverter has the following advantages over the SSTP inverter, the number of switches is reduced by a third; driving circuits are only two as only two branches are controlled. FSTP inverters maximum common mode voltage is just $2 / 3$ of SSTP inverters [1-3].

Despite these advantages, the main drawback of the FSTP inverter is the unbalanced capacitor voltages.
There are two sources imbalance: the first caused by the supply, the second occurs at a low output frequencies where unequal loading of the spilt link occurs for extended period [4].

The Several papers report on FSTPI structure, Most of the reported works on 4-switch, 3-phase FSTP inverter for machine drives did not consider the closed loop vector control scheme, which is essential for high performance drives. Induction motor drives have been thoroughly studied in the past few decades and many vector control strategies have been proposed, ranging from low cost to high performance applications. Traditionally, 6-switch, 3-phase SSTP inverters have been widely utilized for variable speed induction motor (IM) drives [5].

In the past, researchers mainly concentrated on the development of the efficient control algorithms for high performance variable speed IM drives. However, the cost, simplicity and flexibility of the overall drive system which become some of the most 
important factors did not get that much attention to the researchers. That's why, despite tremendous research in this area most of the developed control system failed to attract the industry.

Usually, high performance motor drives used in robotics, rolling mills, machine tools, etc. require fast and accurate response, quick recovery of speed from any disturbances and insensitivity to parameter variations. The dynamic behavior of an AC motor can be significantly improved using vector control theory where motor variables are transformed into an orthogonal set of d-q axes such that speed and torque can be controlled separately [6]. This gives the IM machine the highly desirable dynamic performance capabilities of a separately excited DC machine.

In this paper, experimental investigation of FSTP inverter performance fed sensorless IM drive is verified. The four switches makes the inverter less cost, less switching losses, less chances of destroying the switches due to lesser interaction among switches, less complexity of control algorithms and interface circuits as compared to the conventional SSTP inverter, the control approach reduces the computation for real time implementations. Furthermore, the use of speed sensorless for induction motor drives besides being reduce bulky and increase the robustness [6-9]. However it reduces additional electronics, extra wiring, space and extra cost to the drive system. Speed sensor, also, implies and careful mounting which detracts from the inherent robustness of the drive.

Also a comparison of system performance based on four switch inverter and conventional six switch inverter in terms of speed response and total harmonic distortion of stator currents is presented. Experimental results at different point of operations are presented verifying robustness of sensorless speed estimation at different load levels. Sensorless speed estimation based on four switch inverter is quite acceptable considering its speed response.

\section{DRIVE SYSTEM}

The control scheme of low cost induction motor drive consists of the modeling of the inverter, IM, sensorless control algorithm and the overall system controller, which are discussed in the following subsections:

\subsection{FOUR SWITCH THREE PHASE INVERTER}

This inverter is configured with four switches Q1, Q2, Q3 and Q4, respectively, as shown in Fig. 1. Two output phases are taken from the inverter legs directly where the third output is taken from the midpoint of the two capacitors.

The inverter converts the DC-voltage to a balanced three-phase output with adjustable voltage and frequency. In the analysis, the inverter switches are considered as ideal power switches and it is assumed that the conduction state of the power switches is associated with binary variables Q1 to Q4. Therefore, a binary " 1 " will indicate a closed state, while " 0 " will indicate the open state. Pairs Q1 to Q3 and Q2 to Q4 are complementary and as a sequence: $(\mathrm{Q} 1=1$ Q3, Q4 = 1-Q2). Two control possibilities exist to control the four-switch bridge inverter, i.e., two level current control to force the two controlled phases currents to sinusoidal, or using PWM to control the voltages applied to the three-phase quasisinusoidally. The two- level current control of the four-switch bridge inverter used to control the load current by forcing it to follow a reference one. This is achieved by the switching action of the inverter to keep the current within the hysteresis band. The load currents are measured and compared with respective command currents using two independent hysteresis comparators. The output signals of the comparators are used to activate the inverter power switches.

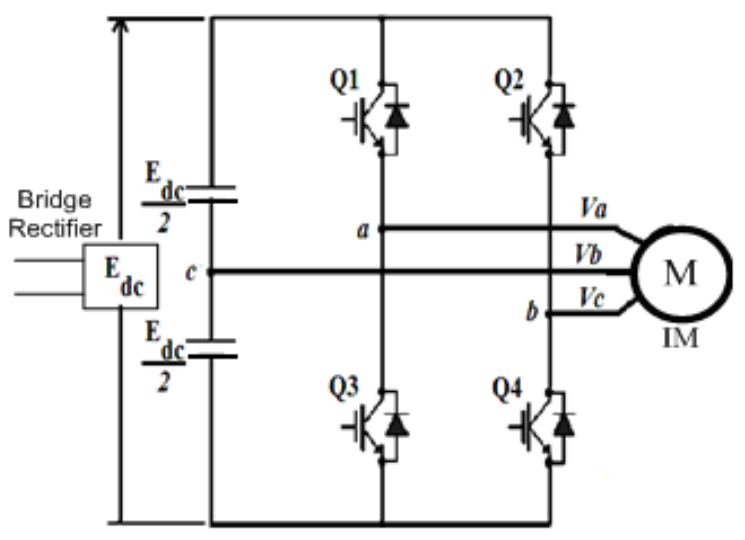

Fig.1 Four switch three- phase inverter with IM

This controller is simple and provides excellent dynamic performance. The modulated phases voltages of four switch inverter are introduced as a function of switching logic Q1, NA1, NB and NB1 of power switches by the following relations [10-11].

$$
\begin{aligned}
& V_{a}=\frac{E_{d c}}{3}(4 N A-2 N B-1) \\
& V_{b}=\frac{E_{d c}}{3}(-2 N A+4 N B-1) \\
& V_{c}=\frac{E_{d c}}{3}(-2 N A-2 N B+2)
\end{aligned}
$$

Where, NA1 and NB1 are complementary of NA and NB. Also, it will be assumed that a stiff voltage is available across the two DC-link capacitors 


\subsection{INDUCTION MOTOR MODEL}

Squirrel-cage induction motor is represented in its de-qe dynamic model [11]. This model represented in synchronous reference frame is expressed as follows;

$$
\left[\begin{array}{c}
\mathrm{V}_{\mathrm{qe}}^{\mathrm{e}} \\
\mathrm{V}_{\mathrm{de}}^{\mathrm{e}} \\
0 \\
0
\end{array}\right]=\left[\begin{array}{cccc}
\mathrm{R}_{\mathrm{s}}+\mathrm{pL}_{\sigma} & \omega_{\mathrm{e}} \mathrm{L}_{\sigma} & \mathrm{p} \frac{\mathrm{L}_{\mathrm{m}}}{\mathrm{L}_{\mathrm{r}}} & \omega_{\mathrm{e}} \frac{\mathrm{L}_{\mathrm{m}}}{\mathrm{L}_{\mathrm{r}}} \\
-\omega_{\mathrm{e}} \mathrm{L}_{\sigma} & \mathrm{R}_{\mathrm{s}}+\mathrm{p} \mathrm{L}_{\sigma} & -\omega_{\mathrm{e}} \frac{\mathrm{L}_{\mathrm{m}}}{\mathrm{L}_{\mathrm{r}}} & \mathrm{p} \frac{\mathrm{L}_{\mathrm{m}}}{\mathrm{L}_{\mathrm{r}}} \\
-\mathrm{R}_{\mathrm{r}} \mathrm{L}_{\mathrm{m}} & 0 & \mathrm{R}_{\mathrm{r}}+\mathrm{pL}_{\sigma} & \left(\omega_{\mathrm{e}}-\omega_{\mathrm{r}} \mathrm{L}_{\mathrm{m}}\right. \\
0 & -\mathrm{R}_{\mathrm{r}} \mathrm{L}_{\mathrm{m}} & -\left(\omega_{\mathrm{e}}-\omega_{\mathrm{r}}\right)_{\mathrm{m}} & \mathrm{R}_{\mathrm{r}}+\mathrm{pL}_{\sigma}
\end{array}\right]\left[\begin{array}{c}
\mathrm{r}_{\mathrm{e}}^{\mathrm{e}} \\
\mathrm{I}_{\mathrm{ds}}^{\mathrm{e}} \\
\lambda_{\mathrm{gr}}^{\mathrm{e}} \\
\lambda_{\mathrm{dr}}^{\mathrm{e}}
\end{array}\right]
$$

The electromechanical equation is also given by;

$$
\mathrm{T}_{\mathrm{e}}-\mathrm{T}_{\mathrm{L}}=\mathrm{J} \frac{\mathrm{d} \omega_{\mathrm{r}}}{\mathrm{dt}}+\mathrm{B} \omega_{\mathrm{r}}
$$

Where, the electromagnetic torque is expressed as;

$$
\mathrm{T}_{\mathrm{e}}=\frac{3}{2} \frac{\mathrm{p}}{2} \cdot \frac{\mathrm{L}_{\mathrm{m}}}{\mathrm{L}_{\mathrm{r}}}\left(\mathrm{I}_{\mathrm{qs}}^{\mathrm{e}} \lambda_{\mathrm{dr}}^{\mathrm{e}}-\mathrm{I}_{\mathrm{ds}}^{\mathrm{e}} \lambda_{\mathrm{qr}}^{\mathrm{e}}\right)
$$

$\mathrm{V}_{\mathrm{qse}}^{\mathrm{e}}, \mathrm{V}_{\text {dse }}^{\mathrm{e}}$ are $\mathrm{q}, \mathrm{d}$-axis stator voltages respectively; $\mathrm{I}_{\mathrm{q} s}^{\mathrm{e}}, \mathrm{I}_{\mathrm{ds}}{ }^{\mathrm{e}}$ are $\mathrm{q}, \mathrm{d}$-axis stator current respectively; $\mathrm{I}_{\mathrm{q}}^{\mathrm{e}}$, $\mathrm{I}_{\mathrm{dr}}^{\mathrm{e}}$ are d,q-axis rotor current respectively; $\lambda_{\mathrm{qr}}^{\mathrm{e}}, \lambda_{\mathrm{dr}}^{\mathrm{e}}$ are d,q-axis rotor flux respectively; $\mathrm{R}_{\mathrm{s}}, \mathrm{R}_{\mathrm{r}}$ are the stator and rotor resistances per phase, respectively; $\mathrm{L}_{\mathrm{s}}, \mathrm{L}_{\mathrm{r}}$ are the self inductances of the stator and rotor respectively; $L_{m}$ is the mutual inductance, $\omega_{r}$ is the rotor speed, $\mathrm{P}$ is the number of poles, $\mathrm{p}$ is the differential operator, $T_{e}$ is the electromagnetic developed torque, $\mathrm{T}_{\mathrm{L}}$ is the load torque, $\mathrm{J}$ is the rotor inertia and $\mathrm{B}$ is the rotor damping coefficient. The motor parameters are given in appendix.

\subsection{SPEED ESTIMATOR BASED MRAS}

Model Reference Adaptive Systems (MRAS) techniques applied in order to estimate rotor speed. This technique is based on the comparison between the outputs of two estimators. The outputs of two estimators may be (the rotor flux, back emf, or motor reactive power).

The estimator that does not involve the quantity to be estimated (rotor speed $\omega_{\mathrm{r}}$ ) is considered as the induction motor voltage model. This model considered to be the reference model (RM). The other model is the current model, derived from the rotor equation, this model considered to be the adjustable model (AM). The error between the estimated quantities by the two models is used to drive a suitable adaptation mechanism which generates the estimated rotor speed [6].

In this paper, the observer depends on the MRAS technique. The speed observer is based on stator current and rotor flux as state variables [8]. The speed estimating procedures from the stator current error are as follows:

First, from the induction motor equation the stator current is represented as in equation (7):

$$
\begin{aligned}
& i_{d s}=\frac{1}{L m}\left[\lambda_{d r}+\omega_{r} T_{r} \lambda_{q r}+T_{r} p \lambda_{d r}\right] \\
& i_{q s}=\frac{1}{L m}\left[\lambda_{q r}-\omega_{r} T_{r} \lambda_{q r}+T_{r} p \lambda_{q r}\right]
\end{aligned}
$$

Using equation (7), and estimated speed instead of measured speed, the stator current is estimated as in equation (8).

$$
\begin{aligned}
& \hat{i}_{d s}=\frac{1}{L m}\left[\lambda_{d r}+\widehat{\omega}_{r} T_{r} \lambda_{q r}+T_{r} p \lambda_{d r}\right] \\
& \hat{i}_{q s}=\frac{1}{L m}\left[\lambda_{q r}-\widehat{\omega}_{r} T_{r} \lambda_{q r}+T_{r} p \lambda_{q r}\right]
\end{aligned}
$$

Form the relationship between the measured stator current and the estimated stator current, the difference in the stator current is obtained as in equation (9).

$$
\begin{aligned}
& i_{d s}-\hat{i}_{d s}=\frac{T_{r}}{L m} \lambda_{q r}\left[\omega_{r}-\widehat{\omega}_{r}\right] \\
& \hat{i}_{q s}-i_{q s}=\frac{T_{r}}{L m} \lambda_{d r}\left[\omega_{r}-\widehat{\omega}_{r}\right]
\end{aligned}
$$

In equation (9), the difference of stator current is sinusoidal value because it is a function of rotor flux. Multiplying by the rotor flux and adding them together;

$$
\begin{aligned}
& \left(i_{d s}-\hat{i}_{d s}\right) \lambda_{q r}=\frac{T_{r}}{L m} \hat{\lambda}_{q r}\left[\omega_{r}-\widehat{\omega}_{r}\right] \\
& \left(\hat{i}_{q s}-i_{q s}\right) \lambda_{d r}=\frac{T_{r}}{L m} 2_{d r}\left[\omega_{r}-\widehat{\omega}_{r}\right]
\end{aligned}
$$

By summing the above two equations.

$$
\left(i_{d s}-\hat{i}_{d s}\right) \lambda_{q r}+\left(\hat{i}_{q s}-i_{q s}\right) \lambda_{d r}=\frac{T_{r}}{L m}\left(\stackrel{2}{\lambda}_{q r}+2_{d r}\right)\left[\omega_{r}-\widehat{\omega}_{r}\right](1)
$$

Hence, the error of the rotor speed is obtained as follows:

$$
\begin{aligned}
& \omega_{r}-\widehat{\omega}_{r}=\left[\left(i_{d s}-\hat{i}_{d s}\right) \lambda_{q r}-\left(i_{q s}-\hat{i}_{q s}\right) \lambda_{d r}\right] / K \\
& \text { Where } \quad K=\frac{T_{r}}{L m}\left(\stackrel{2}{\lambda}_{q r}+\stackrel{2}{\lambda}_{d r}\right)
\end{aligned}
$$

The right hand term seems as the term of speed calculation from adaptive observer, so the speed can be calculated from the following equation [6]; where $\mathrm{K}_{\mathrm{P}}, \mathrm{K}_{\mathrm{I}}$ are the proportional and integral gain constants respectively.

$$
\begin{array}{r}
\widehat{\omega}_{r}=\frac{1}{K}\left[\left(K_{p}\left(i_{d s}-\hat{i}_{d s}\right) \lambda_{q r}-\left(i_{q s}-\hat{i}_{q s}\right) \lambda_{d r}\right)+\right. \\
\left.\left(K_{I} \int\left(i_{d s}-\hat{i}_{d s}\right) \lambda_{q r}-\left(i_{q s}-\hat{i}_{q s}\right) \lambda_{d r}\right)\right]
\end{array}
$$

Fig. 2 shows the block diagram of MRAS system. 


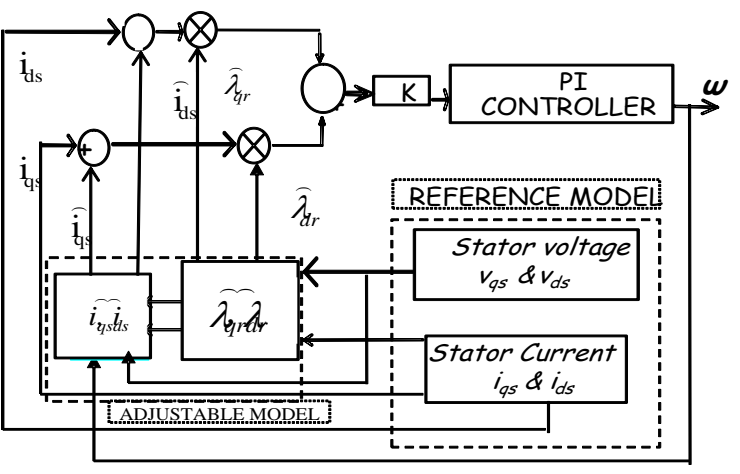

Fig. 2 Block Diagram of Speed Estimation using MRAS

\subsection{OVERALL SYSTEM CONTROLLER}

As shown in Fig. 3 it incorporates the speed controller which receives the error signal between the preset speed and the actual observed speed of the motor shaft and then generates the torque command $\left(\mathrm{T}_{\mathrm{e}}^{*}\right)$ through a proportional integral (PI) speed controller.

This torque command produces the quadrature current command $\mathrm{I}^{*}{ }_{\text {qs }}$ in the synchronous reference frame (SYRF). The direct current $\mathrm{I}_{\mathrm{ds}}^{\mathrm{*e}}$ is sets by the rotor flux level $\lambda^{* \mathrm{e}}{ }_{\mathrm{dr}}$.

This flux level is calculated according to the method described in [8]. The two current commands are then transformed to the stationary reference frame (STRF) with the aid of the calculated command angle $\left(\theta_{e}^{*}\right)$.

This command angle is calculated in such away that aligns the direct-axis of SYRF with the rotor flux axis. The two stator current commands, $\mathrm{I}_{\mathrm{qs}}{ }_{\mathrm{e}}$ and $\mathrm{I}^{{ }^{\mathrm{e}} \mathrm{q}} \mathrm{q}$ in the SYRF are then transformed to STRF and then transformed to three phase references current $\mathrm{i}^{*}{ }_{\mathrm{ar}}, \mathrm{i}^{*} \mathrm{br}$ and $i^{*}{ }_{c r}$ only, two currents reference $i_{a r}$ and $i_{b r}$ required for the hysteresis current controller that generates the switching function for the pulse width modulated voltage source inverter.

\section{EXPERIMENTAL RESULTS}

The experimental results shown are from an induction machine drive coupled to a separately excited DC generator works as a load as shown in Fig. 4. The machine under test was operated under sensorless field oriented speed controlled conditions.

The torque is applied by the DC generator under torque controlled mode. The parameters of the machine under test are given in appendix. The control is done on a digital signal processor board (DSP 1103) plugged into a computer. It performs the vector control algorithm and the hysteresis current controller to generate the pulse sequences for the four switch three phase voltage source inverter.

There is a communication board for transferring and receiving data between the control algorithm on DSP 1103 and the real time system. The induction motor was fed by a voltage source inverter and two current sensors were used for the current measurements. An optional position signal is available from an encoder with 1024 pulses resolution as a reference signal. The proposed excitation was realized using voltage test pulses as described above.

The control algorithm is executed by 'Matlab/Simulink', and downloaded to the board through host computer. The outputs of the board are logic signals, which are fed to the three -phase inverter through driver and isolation circuits. Comparison between the performances of the conventional six switch inverter based sensorless IM drive using MRAS and four switch inverter are experimentally verified at different operating conditions. The response due to a step change in the speed command is used to evaluate the performance in terms of steady state errors and stability both at no load and full load conditions.

Fig. 5.a shows the estimate and measured speed response with a command speed of $90 \mathrm{rad} / \mathrm{sec}$ at no load at $\mathrm{t}=0.9$ second, the speed reference has been changed to $120 \mathrm{rad} / \mathrm{sec}$. It can be seen that the rotor speed is accelerated smoothly to follow its reference value with nearly zero steady state error. Fig. 5.b shows the motor phase current and its reference whereas Fig. 5.c shows the motor three phase current. 
The motor current increase with increasing speed and return back to its normal value.
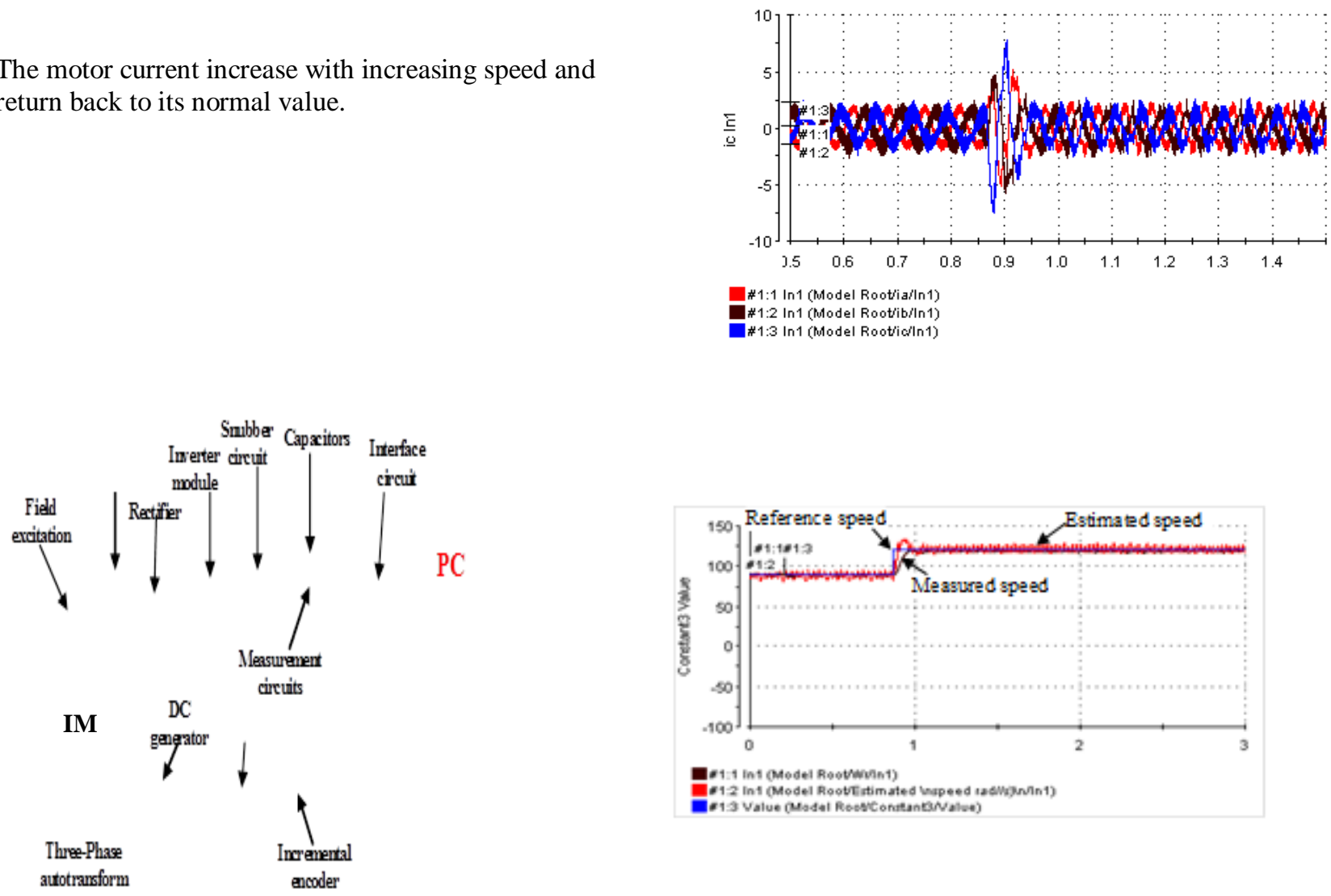

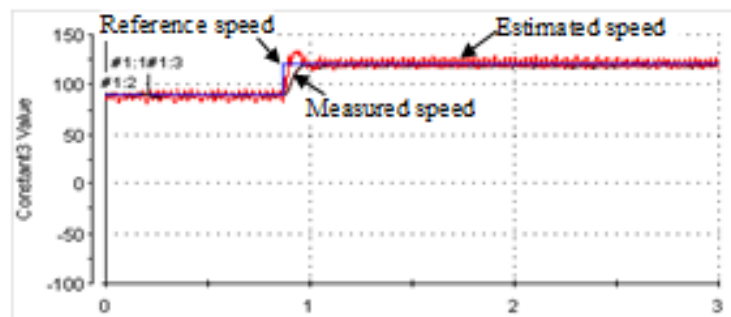

Eat:1 int OMedel Rootwrinst)

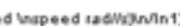

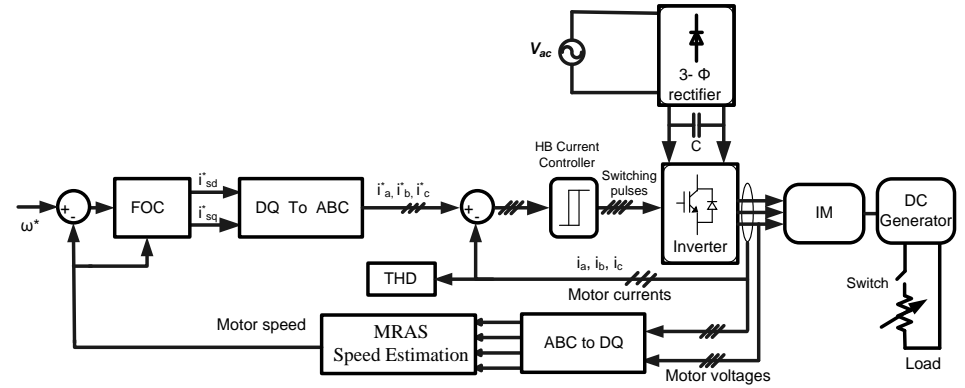

Fig. 3 Block diagram of sensorless speed control

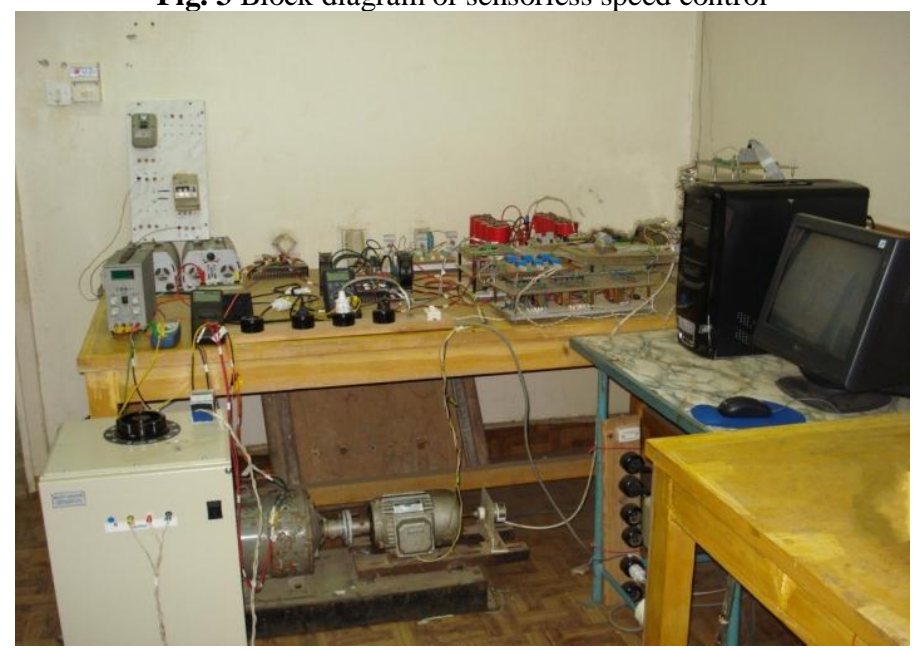

Fig. 4 Experimental-setup

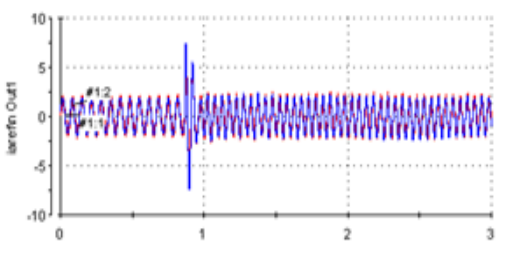

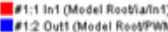

(a)

(b)

(c)

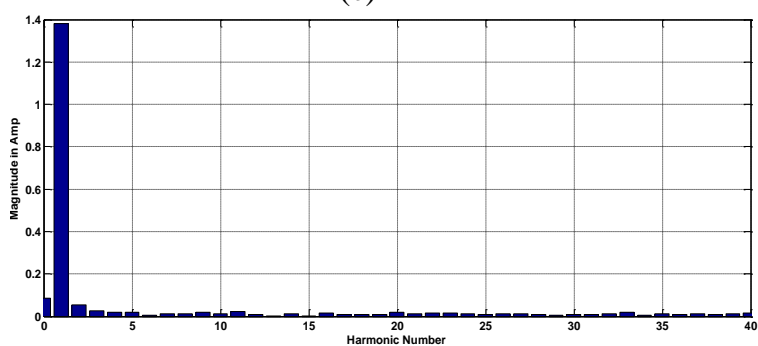

(d)

Fig. 5 Experimental results of FSTP drive at no load (a) Motor Speed; (b) Phase current; (c) Three-phase currents; (d) THD of $i_{a}$. 
These results show a good correlation between the estimated speed signal and its corresponding measured as well as reference speed signals. The total harmonic distortion (THD) of $i_{a}$ is found $27.0386 \%$ as shown in Fig. 5(d)

In order to provide a fair comparison, the speed responses of the conventional SSTP inverter fed IM drive at identical conditions are shown in Fig. 6 it is seen in Fig. 6.a that the estimated and measured speed follows the reference speed, Fig. 6.b shows the motor phase current whereas Fig. 6.c shows three phase motor currents for the step change in speed command. The total harmonic distortion (THD) of $i_{a}$ is found $24.44 \%$ as shown in Fig. 6.d.

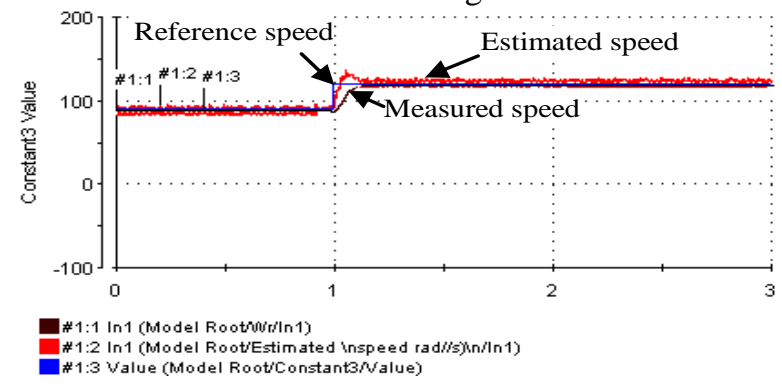

(a)

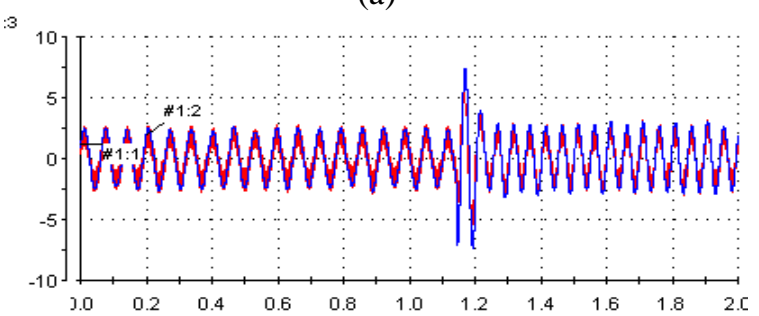

E

1:2 Out1 (Model Root/PWMM/iarefin/Out1)

(b)

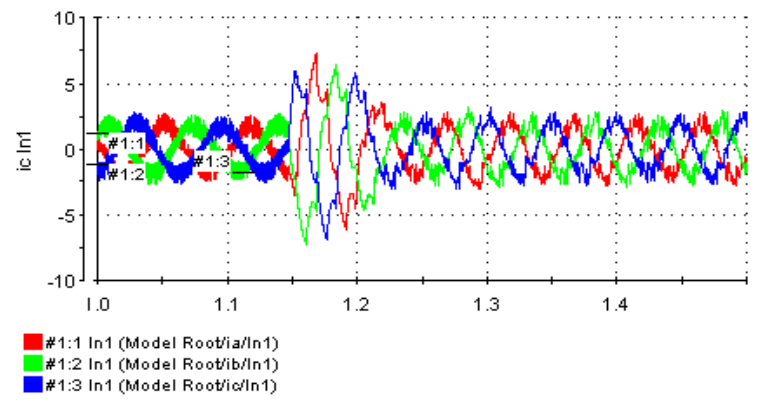

(c)

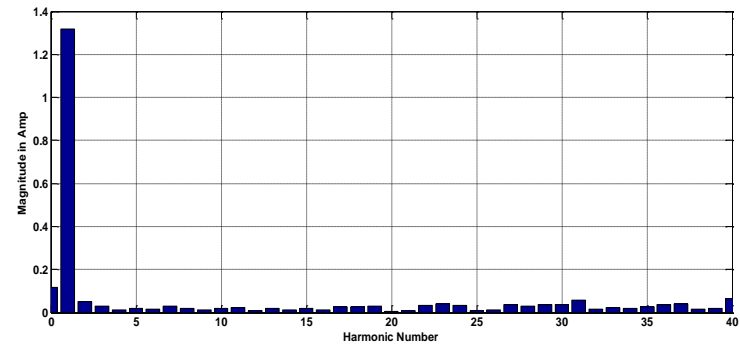

(d)
Fig. 6 Experimental results of SSTP drive at no load (a) Motor Speed; (b) Phase current; (c) Three-phase current; (d) THD of $i_{a}$.

Another case to study the drive response applying step change in the reference speed at full load condition. Fig. 7 shows the drive response when motor fed from FSTP inverter. The motor is running at $90 \mathrm{rad} / \mathrm{sec}$, at $\mathrm{t}=0.9$ second, the reference speed has been changed to $120 \mathrm{rad} / \mathrm{sec}$ in step, it shows that a perfect speed tracking with approximately zero steady state error. The response indicates how well the controller succeeds in forcing the actual rotor speed to follow the desired reference speed with nearly zero steady-state error. Fig. 7.b shows motor phase current with reference current, whereas Fig. 7.c shows the motor three phase current, it increases with step up of speed reference.

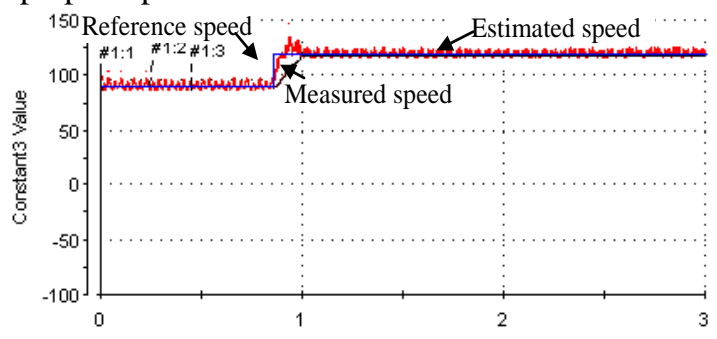

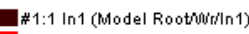

\#1:2 In 1 (Model RootiEstimated inspeed rad//s)in/ln1)

(a)

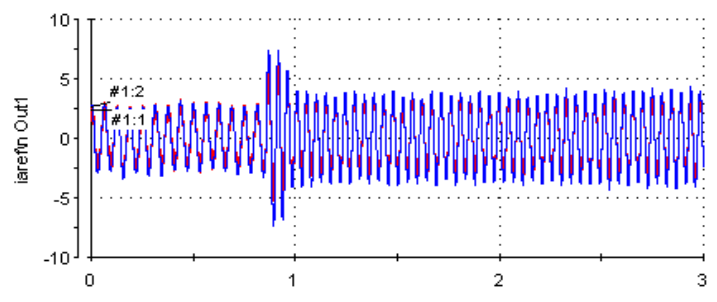

\#1:1 $\ln 1$ (Model Rootia/ln 1 )

*1:2 Out1 (Model Root/PWMM/iarefin/Out1)

(b)

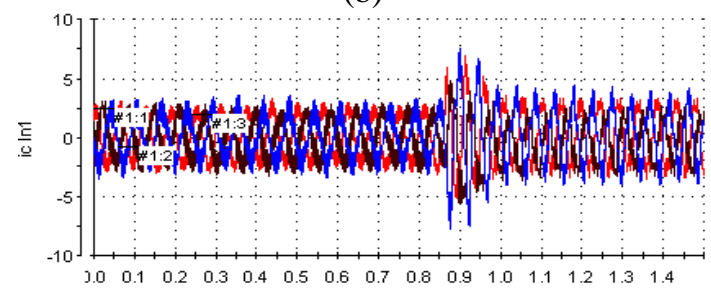

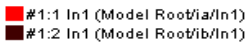

E $* 1: 3 \ln 1$ (Model Rootííln 1 )

(c)

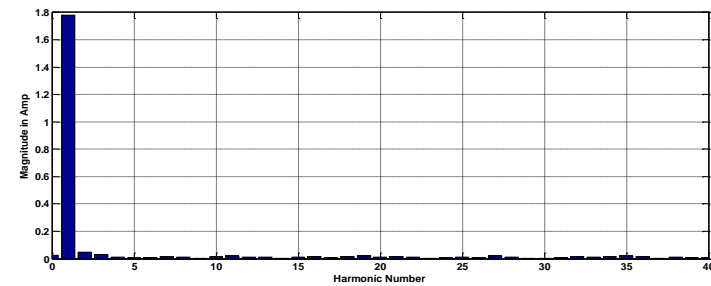

(d) 
Fig. 7 Experimental results of FSTP drive at full load (a) Motor Speed; (b) Phase current; (c) Threephase currents; (d) THD of $i_{a}$

The total harmonic distortion (THD) of $i_{a}$ is found $23.5169 \%$ as shown in Fig.7.d. The same results in Fig. 8 are taken when the motor is fed from SSTP conventional inverter at identical conditions.

Fig. 8.a shows that the estimated and measured speed follows the reference speed with nearly zero steady state error. Fig 8.b shows the motor phase current and reference current, whereas Fig. 8.c shows the motor three phase currents for the step change in speed command. The total harmonic distortion (THD) of $\mathrm{i}_{\mathrm{a}}$ is found $20.2548 \%$. However, after considering all the results, it is seen that the proposed inverter based drive phase currents suffers from slight unbalance in which cause relatively higher speed vibrations as compared to the conventional SSTP inverter fed drive.

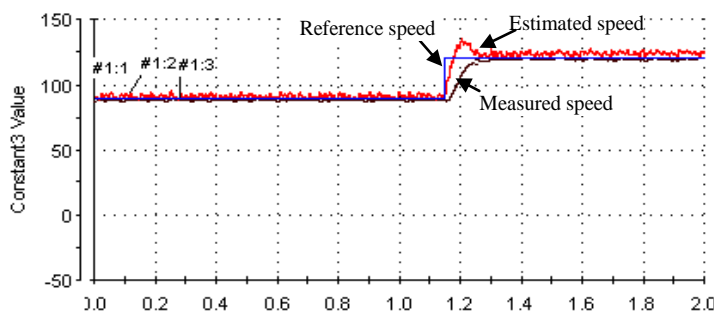

E*1:1 In 1 (Model Roothivilin 1 )

\#1:2 $\ln 1$ (Model Root'Estimated inspeed rad//s)(n/ln1)

(a)

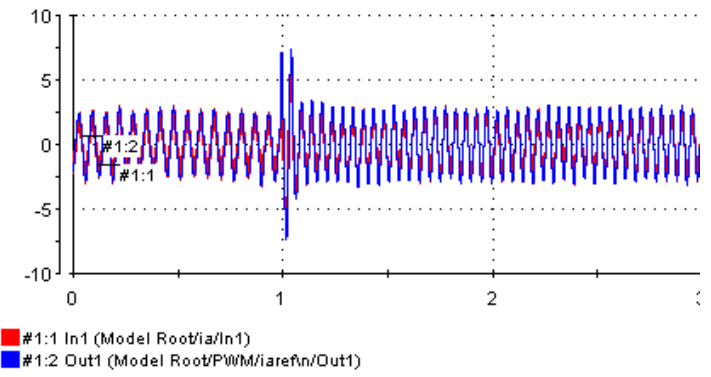

(b)

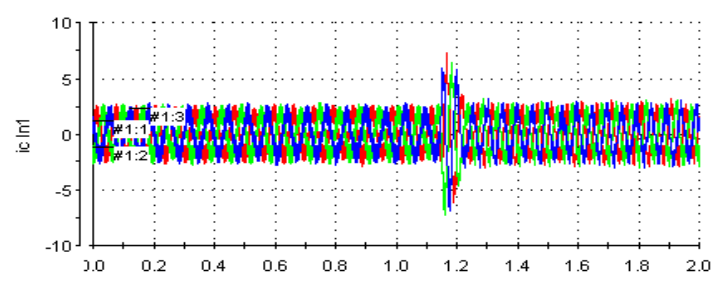

E $\# 1: 1 \ln 1$ (Model Rootiaziln 1 )

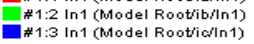

(c)

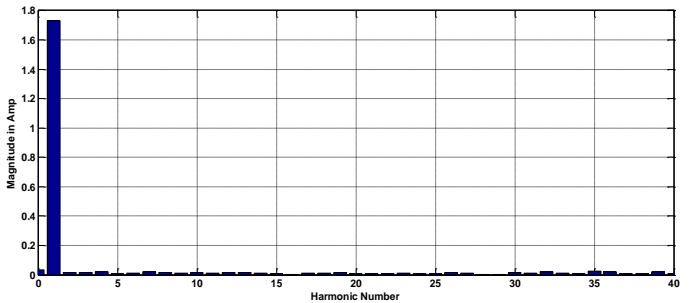

(d)

Fig. 8 Experimental results of SSTP drive at full load (a) Motor Speed; (b) Phase current; (c) Three-phase currents;

(d) THD of $i_{a}$

Also, the high switching of motor current makes the estimated speed signal is very noisy in the proposed FSTP drive. The total harmonic distortion of the proposed inverter is slightly increased as compared to conventional inverter. It is found that the performance of the proposed inverter based drive is much closer to that of the conventional inverter and can successfully perform sensorless speed control.

\section{CONCLUSION}

The experimental investigation of FSTP inverter fed IM drive using sensorless speed estimator based on MRAS algorithm has been presented and experimentally implemented. The FSTP inverter fed IM drive system reduces the cost of the inverter, the switching losses and the complexity of the control algorithms as compared with the conventional SSTP inverter based drive. The vector control scheme has been incorporated in the integrated drive system to achieve high performance. The MRAS as a speed estimator verified the robustness of the FSTP inverter approach. Performance of the sensorless speed control using FSTP inverter fed IM drive has been experimentally investigated. A comparison between the performances of the FSTP inverter fed IM drive with a conventional SSTP inverter fed IM drive has been presented in terms of the speed and total harmonic distortion under identical operating conditions. The FSTP inverter fed IM drive has been ensuring robust and acceptable for low-cost applications such as automotive and home appliance applications.

\section{REFERENCES}

[1] Bassem El Badsi, Badii Bouzidi, and Ahmed Masmoudi, "DTC Scheme for a Four-Switch Inverter-Fed Induction Motor Emulating the SixSwitch Inverter Operation" IEEE Trans. Power Electron.,vol 28, no. 7, pp. 3528-3538, July 2013.

[2] M. B. R. Correa, C. B. Jacobina, E. R. C. Da Silva, and A. M. N. Lima."A General PWM Strategy for Four-Switch Three-Phase Inverters" 
IEEE Trans. on Power Electronics, Vol. 21, No. 6, Nov. 2006, pp 1618-1627.

[3] P.Q. Dzung, L.M. Phuong, P.Q. Vinh, N.M. Hoang,T.C. Binh, "New Space Vector Control Approach for Four Switch Three Phase Inverter", International Conference on Power Electronics and Drive Systems- PEDS 2007, Bangkok, Thailand, 2007.

[4] A. Khlaief, M. Bendjedia, M. Boussak, and M. Gossa, "A nonlinear observer for highperformance sensorless speed control of IPMSM drive," IEEE Trans. Power Electron., vol. 27, no. 6, pp. 3028-3040, June 2012.

[5] G. Foo and M. F. Rahman, "Sensorless direct torque and flux-controlled IPM synchronous motor drive at very low speed without signal injection," IEEE Trans. Ind. Electron., vol. 57, no. 1, pp. 395-403, Jan. 2010.

[6] M.K. Metwally “ Sensorless Speed and Position Control with DTFC of Induction Motor using Four Switch Three Phase Inverter and Adaptive Flux Observer," International Journal of Electrical \& Computer Sciences IJECS-IJENS vol. 12, no, 5, pp.38-45, Oct 2012.

[7] Y. Inoue, Y. Kawaguchi, S. Morimoto, and M. Sanada, "Performance improvement of sensorless IPMSM drives in a low-speed region using online parameter identification," IEEE Trans. Ind. Electron., vol. 47, no. 2, pp. 798-804, Mar./Apr. 2011.

[8] M. Hasegawa and K. Matsui, "Position sensorless control for interior permanent magnet synchronous motor using adaptive flux observer with inductance identification," IET Electr. Power Appl., vol. 3, no. 3, pp. 209-217, May 2009.

[9] Jin-Su Jang, Byoung-Gun Park, Tae-Sung Kim, Dong Myung Lee, Dong-Seok Hyun, "Sensorless Control of Four-Switch Three-Phase PMSM
Drive Using Extended Kalman Filter" IEEE IECON Conference, pp.1368-1372, June 2008.

[10] J. Klima, "Analytical Investigation of an Induction Motor Fed From Four-Switch VSI With a New Space Vector Modulation Strategy," IEEE Trans. Power Electron., vol. 21, no. 6, pp. 16181617, Nov. 2006.

[11] M. N. Uddin, T. S. Radwana, and M. A. Rahman, "Performance analysis of a 4-switch, 3-phase inverter based cost effective IM motor drives," Electrical and Computer Engineering, Canadian Conference, pp. 85-88, 2004.

\section{APPENDIX}

The parameters of applied induction machine

\begin{tabular}{ll}
\hline Rated power & $1.1 \mathrm{kw}$ \\
Rated load torque & $7.5 \mathrm{~N} . \mathrm{m}$. \\
No. of poles & 4 \\
Stator resistance & $7.4826 \mathrm{ohm}$ \\
Rotor resistance & $3.6840 \mathrm{ohm}$ \\
Rotor leakage inductance & $0.0221 \mathrm{H}$ \\
Stator leakage inductance & $0.0221 \mathrm{H}$ \\
Mutual inductance & $0.4114 \mathrm{H}$ \\
Supply frequency & $50 \mathrm{~Hz}$ \\
Motor speed & $1420 \mathrm{r} . \mathrm{p} . \mathrm{m}$. \\
Supply voltage & $380 \mathrm{volts}$ \\
Inertia & $0.02 \mathrm{~kg} \cdot \mathrm{m}^{2}$ \\
\hline
\end{tabular}

List of Symbols;

$\mathbf{L}_{\boldsymbol{\sigma}}=\mathbf{L}_{\mathbf{s}}-\frac{\mathbf{L}_{\mathbf{m}}^{2}}{\mathbf{L}_{\mathbf{r}}}$ The leakage inductance

$\mathrm{T}_{\mathrm{r}}=\frac{\mathrm{L}_{\mathrm{r}}}{\mathrm{R}_{\mathrm{r}}} \quad$ Rotor time constant

$\sigma=1-\frac{\mathrm{L}_{\mathrm{m}}^{2}}{\mathrm{~L}_{\mathrm{s}} \mathrm{L}_{\mathrm{r}}} \quad$ Leakage coefficient 